\title{
Assuring clinical genetic services for newborns identified through U.S. newborn screening programs
}

Celia I. Kaye, $\mathrm{MD}, \mathrm{PhD}^{1,5}$, Judith Livingston, $M E d^{2,5}$, Mark A. Canfield, $P h D^{3}$, Marie Y. Mann, MD, MPH ${ }^{4}$, Michele A. Lloyd-Puryear, $\mathrm{MD}, \mathrm{PhD}^{4}$, and Bradford L. Therrell, Jr., $P h D^{2,5}$

\begin{abstract}
Purpose: The study purpose was to determine whether U.S. newborn screening and/or genetics programs systematically document whether newborns and their families, identified with genetic disorders through newborn dried blood spot screening, receive clinical genetic services. Methods: Nineteen state genetic plans were reviewed and a 30-question survey was administered to 53 respondents, including state newborn screening program coordinators and state genetics program coordinators in 36 states and principal investigators of 5 Health Resources and Services Administration-designated regional genetic and newborn screening collaboratives. Results: Survey findings indicate that none of the state newborn screening and/or state genetics programs routinely tracked patient-level data on clinical genetic services for newborns identified with all of the genetic and congenital conditions for which their programs screened. Few programs could provide information systematically on whether patients were referred for, or received, genetic counseling. Conclusions: Systematic tracking of clinical genetic services for newborns identified by newborn screening programs is desirable and manageable. Recent national guidelines recommend tracking genetic counseling in newborn screening follow-up. The communications processes that state programs currently use to obtain follow-up reports from subspecialists could be augmented with clinical genetic service questions. Programs should be encouraged and supported in the efforts to track genetic services for the benefit of newborns and their families. Genet Med 2007:9(8):518-527.
\end{abstract}

Key Words: newborn screening, follow-up genetic services, genetic counseling, data collection

State newborn screening programs were the first population-based screening programs for genetic disorders, signaling the integration of genetic knowledge into public health. ${ }^{1}$ After more than 40 years, newborn blood spot screening (NBS) has become recognized as an essential preventive public health program $^{2,3}$ and a model for public health-based population genetic screening. ${ }^{4}$

NBS is a system composed of education, screening, followup, diagnosis, management, program evaluation, and continuous quality improvement. ${ }^{1-5}$ The system provides for early identification of conditions for which timely interventions can help eliminate or reduce associated mortality, morbidity, and disabilities. The American Academy of Pediatrics Task Force

\footnotetext{
From the ${ }^{1}$ Office of Education, University of Colorado School of Medicine, Denver, Colorado; ${ }^{2}$ Department of Pediatrics, University of Texas Health Science Center at San Antonio, Texas; ${ }^{3}$ Birth Defects Epidemiology and Surveillance Branch, Texas Department of State Health Services, Austin, Texas; ${ }^{4}$ Maternal and Child Health Bureau, Health Resources and Services Administration, Rockville, Maryland; and ${ }^{5}$ National Newborn Screening and Genetics Resource Center, Austin, Texas.

Disclosure: The authors declare no conflict of interest.

Judith Livingston, MEd, Department of Pediatrics, University of Texas Health Science Center at San Antonio; National Newborn Screening and Genetics Resource Center, 1912 W. Anderson Lane; Suite 210, Austin, TX 78757.

Submitted for publication March 28, 2007.

Accepted for publication May 18, 2007.

DOI: 10.1097/GIM.0b013e31812e6adb
}

on Newborn Screening's report on NBS (2000) began with underlying assumptions that the primary objective of each state's NBS system should be to ensure that every newborn receives appropriate and timely services and, further, that state public health agencies should assume responsibility for assessment, assurance, and policy development in the context of $\mathrm{NBS}^{3}$

Clinical genetic services are among the timely and appropriate services required by newborns and their families with conditions identified through NBS. 1,6,7 For example, a family with a newborn diagnosed with congenital adrenal hyperplasia should receive genetic counseling on recurrence risk in future offspring, as well as the appropriate endocrinology subspecialty services. If, as previously noted, it is the responsibility of state public health agencies to ensure appropriate and timely services, it seems reasonable that state programs involved in NBS would document whether newborns and their families received the requisite genetic services.

Monitoring and documenting provision of clinical genetic services are included in the NBS follow-up activities. Shortterm follow-up (STFU) and long-term follow-up (LTFU) are vital in facilitating early diagnosis and intervention for affected newborns and their families. STFU and LTFU have been variously defined, with definitions changing over time. ${ }^{1,5,8}$ However, the end point for STFU remains generally understood to be when a definitive diagnosis of a condition identified 
through NBS is made, and there is documentation that appropriate treatment has been initiated. LTFU begins where STFU ends.

State NBS programs have traditionally focused on STFU, taking extraordinary measures to prevent any newborns from being lost to follow-up and documenting all communications concerning the screening, diagnosis, and referral of newborns. Most states routinely report quantitative information about these follow-up activities to the National Newborn Screening and Genetics Resource Center (NNSGRC). ${ }^{9}$

Although the Council of Regional Networks for Genetic Services NBS guidelines for follow-up (2000) stated that "longterm tracking and outcome evaluation are the responsibilities of the NBS program," which includes monitoring of clinical genetic services, needs improvement. ${ }^{3,4,8,10}$ A 1998 review of NBS for sickle cell disease noted that although evaluations of pediatric outcomes after NBS are important to ensure provision and receipt of necessary services, data to assess program goals are incomplete for most disorders identified by NBS. ${ }^{11}$ In 2006, the American College of Medical Genetics Newborn Screening Expert Group, convened at the request of the Health Resources and Services Administration (HRSA)/Maternal and Child Health Bureau $(\mathrm{MCHB})$, reported that "for the longer term of intervention and treatment, there is usually insufficient information shared between state NBS programs and health care providers, and contact beyond the initial treatment phase rare." ${ }^{\prime \prime}$ In a recent study of LTFU practices among state NBS programs, researchers concluded that LTFU remains an underdeveloped component of NBS generally, and the role that state NBS programs should play in it remains unclear. ${ }^{12}$ Given the variable nature of LTFU, we wanted to determine whether state NBS and/or state genetics programs systematically document whether newborns and their families, identified with genetic disorders through NBS, received clinical genetic services.

\section{MATERIALS AND METHODS}

In the current study of state activities, we reviewed available genetics plans from 19 states, most of which were developed with support from the HRSA/MCHB. In addition, we surveyed state and regional genetics leaders. The purpose of the review of state plans was to help identify which states, if any, had or planned data collection activities that would help answer questions about clinical genetic services for newborns identified through NBS. Relevant data collection activities were abstracted and compiled in a summary discussing each plan.

An ad hoc group of experts, with representation from the American Academy of Pediatrics Committee on Genetics and Section on Genetics and Birth Defects, and NNSGRC cooperative agreement partners developed a definition for adequate genetic services specific to the project (Table 1). This definition represents services that are expected to be provided to the newborn screening population. An epidemiologist assisted in the development of the survey instruments that were administered to state NBS follow-up coordinators, state genetics coordina-
Table 1

National Newborn Screening and Genetics Resource Center working definition of adequate genetic services

Genetic services for individuals and their families identified as affected by newborn screening will include an integrated clinical and laboratory services system that offers the following core functions and associated attributes.

Core functions:

Accurate clinical diagnosis

Accurate genetic laboratory diagnosis

Risk estimation

Genetic counseling

Linkage of patient to genetic service providers

Linkage of patient with medical home

Communication with other specialty providers

Maintenance of a DNA storage service

Attributes of the Genetic Service System (may be ongoing simultaneously with core functions):

A family-based approach where required

Accessible information for families, other health professionals, and patient support groups

Support to individuals and families

Prevention of a disorder or complications including family follow-up (e.g., anticipatory care, prenatal care, and testing)

Participation in research and clinical quality assurance

Maintenance of confidential family records

tors, and HRSA/MCHB-funded regional genetic and NBS service collaborative principal investigators (RCPIs) (Table 2). The instruments for state NBS follow-up coordinators (Table 3 ) and state genetics coordinators asked the same questions

Table 2

Newborn screening and genetic roles and working relationships

\begin{tabular}{|c|c|}
\hline Personnel category & Working relationships \\
\hline $\begin{array}{l}\text { Newborn screening } \\
\text { follow-up } \\
\text { coordinator }\end{array}$ & $\begin{array}{l}\text { Employed by state public health program for } \\
\text { coordination and administration of } \\
\text { newborn screening follow-up services; } \\
\text { acts as interface between newborn } \\
\text { screening laboratory and providers } \\
\text { responsible for diagnosis and care of } \\
\text { newborn; may also serve in capacity as } \\
\text { state genetics coordinator }\end{array}$ \\
\hline $\begin{array}{l}\text { State genetics } \\
\text { coordinator }\end{array}$ & $\begin{array}{l}\text { Employed by state public health program for } \\
\text { coordination and administration of state } \\
\text { genetic services; may also serve in capacity } \\
\text { as newborn screening follow-up } \\
\text { coordinator }\end{array}$ \\
\hline $\begin{array}{l}\text { Regional genetics } \\
\text { principal } \\
\text { investigator }\end{array}$ & $\begin{array}{l}\text { Recipient of U.S. government grant for } \\
\text { direction and oversight of activities of one } \\
\text { of seven regional genetics and newborn } \\
\text { screening service collaboratives; the } \\
\text { multistate regional collaboratives address } \\
\text { newborn screening and genetics issues } \\
\text { from a regional/national perspective }\end{array}$ \\
\hline
\end{tabular}


Table 3

Survey questions for state newborn screening follow-up coordinators

1. Does your state collect information on clinical genetic services provided in response to conditions identified through newborn screening?

$\square$ YES

NO

If YES, can you provide data on:

Number/percent of newborns identified through newborn screening, by condition, referred for genetic services?

$\square$ YES $\quad \square$ NO

Number/percent of newborns identified through newborn screening, by condition, who received genetic services?

$\square$ YES $\quad \square$ NO

Outcome indicators for children of a particular birth cohort (or delivery year) and identified through NBS who received genetic services?

$\square$ YES $\quad \square$ NO

Number/percent of patients, by condition, identified through newborn screening who are

tracked more than one year? $\square$ YES $\square$ NO

For patients tracked more than one year, do you have information on outcomes by condition?

$\square$ YES $\quad \square$ NO

If YES, how is this information collected?

2. If $\mathrm{NO}$, can you identify other source(s) for this data in your state (e.g. subspecialists; referral centers)?

\section{YES $\square$ NO}

3. If NO, do you have plans to collect this information? $\square$ YES $\square$ NO Comment/describe:

Timeline for projects:

4. What are other source(s) for these data in your region?

5. Do you collect (and can you provide) data in your state to determine the following for each patient/family identified through newborn screening:

\begin{tabular}{l}
\hline \multicolumn{1}{c}{ Attribute } \\
\hline A. Accuracy of clinical diagnosis made \\
\hline B. Accuracy of laboratory diagnosis made \\
\hline C. If patient/family is referred for genetic \\
counseling \\
D. If patient/family received genetic \\
counseling \\
E. If families receive risk estimation as \\
part of genetic counseling \\
\hline F. Location/provider to which \\
patient/family was referred \\
\hline G. If patients/families were linked with \\
genetic service providers and who they \\
were \\
\hline H. If patients/families were linked to a \\
medical home \\
I. If communication occurred between \\
state program and other specialty providers
\end{tabular}


Table 3

Continued

J. If communication occurred between genetic service providers and other specialty providers

K. Other:

L. Other:

6. Does the state maintain a DNA storage service? $\square$ YES

Comments:

7. Are the following services/activities carried out for newborn screening disorders by the genetic services system in your state?

\begin{tabular}{l}
\multicolumn{1}{c}{ Service/Activity } \\
\hline A. Use a family-based \\
approach to genetic \\
services? \\
\hline B. Make information for \\
families, health care \\
providers, and patient \\
support groups \\
accessible? \\
\hline C. Support for \\
individuals/families? How? \\
\hline D. Provide services to \\
prevent disorders or \\
complications? (e.g. \\
prenatal care/testing) \\
\hline E. Participate in research? \\
\hline F. Participate in clinical \\
quality assurance? \\
\hline G. Maintain confidentiality \\
of family records? How? \\
\hline H. Other: \\
\hline I. Other:
\end{tabular}

8. Does your newborn screening data system link with any of these clinical subspecialties?

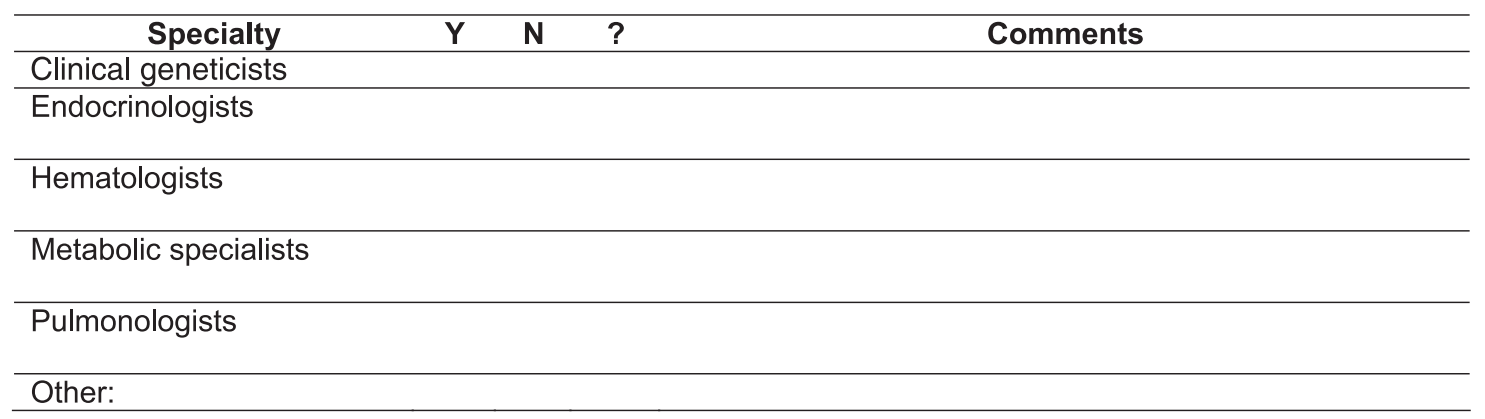

9. Is your computerized tracking system for newborn screening follow-up integrated with other state data systems?

$\square$ YES $\square$ NO $\square$ Unknown

Comments:

10. If so, which systems?

11. If there are additional questions that arise during this data collection project, may we contact you again?

NBS, newborn blood spot screening. 
using a similar format with only minor changes appropriate to the target audience. The survey for the RCPI used a similar format with questions worded to reflect a regional perspective. The survey instruments were piloted with one RCPI (by phone), one state genetics coordinator, and four NBS follow-up coordinators (in-person). All pilot participants were contacted in advance and provided a copy of the expert definition of genetic services along with a survey instrument. Survey instruments were revised on the basis of input from pilot participants.

NNSGRC administered a brief survey of 50 state NBS follow-up coordinators to identify states that collect data on clinical genetic services for conditions identified through NBS. This information was triangulated with the results from a qualitative research project on $\mathrm{LTFU}^{12}$ to further refine the list of candidate states. States were excluded from further surveys if they reported they do not do LTFU and/or if they reported they do not collect data on clinical genetic services for newborns identified through NBS. The final list of survey candidates included 40 states and the 7 regional genetic and newborn screening service collaboratives.

Surveys were administered to 53 respondents in 36 of the 40 states and 5 of the 7 regional genetic and newborn screening service collaboratives, including 20 state NBS follow-up coordinators, 18 state genetics coordinators, 10 dual role (NBS/ genetics) coordinators, and 5 RCPIs. All respondents were queried by e-mail about their willingness to participate in the survey after receiving a copy of the survey instrument and the project definition of genetic services. By surveying both state NBS follow-up coordinators and state genetics coordinators, we were able to ensure that each state surveyed had a complete set of responses. In some states, the division of labor between NBS and genetics is such that NBS follow-up coordinators could not answer questions related to statewide genetic services system and state genetics coordinators could not answer questions related to NBS. In these instances, both individuals were surveyed.

Surveys were administered by phone to 44 participants, inperson to 5 participants, and by e-mail to 4 participants. Survey responses were entered into spreadsheets within 1 to 2 days of collection by the same individual who conducted the survey. During the phone and in-person interviews, the respondents often had qualifying comments in response to a number of the survey questions. The qualifying comments and clarifying responses were recorded and validated with the respondents. Additional communication by phone and e-mail was conducted with the four respondents who elected to reply initially by e-mail only.

Data from the surveys were tabulated into a set of statespecific tables and combined into a comprehensive set of data tables. All respondents were provided copies of their state-specific data to validate. Surveys were conducted and data were validated between October 2005 and June 2006. Survey responses were collected with minimal focus on statistical analyses. The validity of each question was inferred using the critical review and input of clinicians and program staff with subject matter expertise. Such "content validity" is rarely tested formally. ${ }^{13}$

\section{RESULTS}

Of the 40 states and 7 regional genetic and newborn screening service collaboratives identified for the survey, 35 states and 5 regional genetic and newborn screening service collaboratives completed the survey and validation processes. One additional state participated in the survey but did not validate data. In 23 of the 35 states that participated fully, both the state NBS follow-up coordinator and state genetics coordinator were surveyed.

All 35 states that validated their responses screened for metabolic, sickle cell disease/hemoglobinopathies, and endocrine disorders. Eight of the 35 states screened for cystic fibrosis at the time of the survey. Of these states:

- Twenty-five (71\%) reported being able to provide data on genetic services for metabolic disorders. Of these states, seven indicated they could access genetic services data through a database. The other states indicated that they could access the data through a paper reporting system or patient records.

- Fourteen states (40\%) reported being able to provide data on genetic services for sickle cell disease/hemoglobinopathies; two through a database and the others through a paper reporting system or patient records.

- Nine states $(26 \%)$ reported being able to provide data on genetic services for endocrine disorders through a paper reporting system or patient records; and

- Five of eight states (63\%) reported being able to provide data on genetic services for cystic fibrosis through a paper reporting system or patient records.

Patient records were considered accessible by virtue of the state program providing services directly or because the state contracted and/or worked closely with genetic or subspecialty centers and could request data or access patient records.

Twenty-five of 35 states (71\%) reported collecting data on each patient/family referred for genetic counseling, and 21 states $(60 \%)$ reported collecting data on each patient/family that received genetic counseling. However, there were numerous qualifying comments with respondents' responses. For example, some states indicated they collected data on genetic counseling for one group of disorders only-metabolic diseases as opposed to hemoglobinopathies. Other states indicated they assumed genetic counseling was provided because a referral was made to a genetic center.

Five of 35 states (14\%) reported that genetic services data could be provided in aggregate from state-contracted genetic service providers. Two states reported that genetic services data were captured in other databases at the health department but not linked directly with NBS.

After a careful review of respondents' responses and qualifying comments, it was determined that none of the 35 state NBS and/or state genetic programs routinely tracked patient- 
level data on clinical genetic services for newborns identified with all of the genetic conditions for which their programs screen. No state tracked data on clinical genetic services as defined in Table 1. For details on genetic services for individual newborns, patient records would have to be retrieved.

Of states that tracked some disorders, tracking methods varied also. Eight states (23\%) reported methods for further documenting patients who were referred and/or received genetic counseling. Of these, five states tracked genetic counseling using information from follow-up reporting forms with two of these states entering the information into a searchable database. A sixth state reported that genetic counseling was part of an intensive first visit for metabolic conditions identified through tandem mass spectrometry. Information documenting that genetic counseling occurred was accessible because the individual providing the counseling was contracted by the state which included this in the terms of the contract. Information on other metabolic disorders was also available because of the close working relationship with the university genetic centers. The seventh state reported the ability to track genetic counseling through contract with a geneticist and the use of state program care coordinators for metabolic, endocrine, and sickle cell/hemoglobinopathy disorders. Although there was no care coordinator for cystic fibrosis, the program used an extensive reporting form to obtain information on genetic counseling. The eighth state could track referral for genetic evaluation through a searchable database and genetic counseling through patient records that the state NBS program maintains. In addition to these eight states, one state reported a special federally funded study and database for tracking LTFU on tandem mass spectrometry.

Five states (14\%) reported that their NBS data systems were linked to those of clinical subspecialists, including clinical geneticists, endocrinologists, hematologists, metabolic specialists, and pulmonologists. These five states were not the same as those in the aforementioned discussion on tracking genetic counseling. Of these, two states reported linkage with clinical geneticists and metabolic specialists; one state reported a readonly system for endocrinology follow-up and the development of a web-based system interface between the state NBS follow-up program and metabolic specialists; one state had developed an agreement by which metabolic, state program, and university-based genetic providers could input and read information on STFU; and one state reported linkage with all the above subspecialties, except pulmonology. An additional nine states $(25 \%)$ gave a qualified "no," explaining, for example, that pediatricians could access their system for newborn screening reports in read-only format or that access by genetics clinics was in the discussion phase.

Seven states $(20 \%)$ reported that their computerized NBS follow-up system was integrated with other state data systems. Four of these states reported linking with newborn hearing screening only; two states reported linking with vital records and newborn hearing screening; one state reported that NBS data went into the birth defects registry and was "partially" linked to hearing screening; and one state reported linking with prenatal screening and electronic matching with vital records and birth defects registry. Twenty states (57\%) gave qualified "no" responses with comments indicating intent or efforts toward linkage with at least one other state data system. Of the remaining eight states, seven answered "No" without adding qualifiers and one was unsure.

Although not a direct question on the survey, 21 states (60\%) reported having contractual arrangements for genetic services with clinicians who care for newborns referred for genetic services, including those with NBS-identified conditions. This information was provided through respondents' explanations of other potential sources of data. Significant variability was reported among states with regard to which subspecialty groups and individual providers received state support. For example, some states funded university-based genetic centers that provided care for all conditions, some states only had agreements with metabolic or sickle cell centers, and some states paid for personnel in centers. One state provided matching state funds for sickle cell centers and partially subsidized metabolic centers. There was a public-private partnership in which state-funded employees worked in a private setting, arrangements in which university-based providers had dual roles with state programs, and states that contracted with universitybased providers in other states who were in closer proximity to families seeking care. Four of the nine states that indicated being able to access information on endocrine conditions reported having contractual agreements that included endocrinology.

\section{DISCUSSION}

In a 2001 study of genetic counseling and risk communication services of state NBS programs, Farrell et al. ${ }^{14}$ found that of the 46 state NBS program respondents, 35 (75\%) answered that they "routinely" provide counseling services to families of affected infants. In our study, 25 states (71\%) answered "Yes" to collecting data on whether individual patients/families were referred for genetic counseling, and 21 states (60\%) answered "Yes" to collecting data on whether patients/families received genetic counseling. However, we found that the number of state programs that could actually provide this information was eight (23\%) (Table 4). Although the majority of states believe they are providing genetic counseling services, in fact, few state programs collect data to document these services.

In 1997, the HRSA/MCHB-supported Council of Regional Networks for Genetic Services produced Guidelines for Clinical Genetic Services for the Public's Health with the express purpose of providing state and territorial public health agencies with an outline of suggested components for a genetic services system, primarily to facilitate the integration of genetic

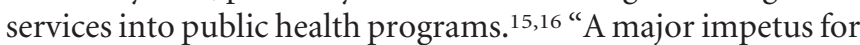
the preparation of the guidelines was a broadly held perception that genetic services are not well integrated into the public health programs of most states, nor are clinical or program databases for genetic services effectively used in the design, evaluation, and monitoring of public health genetics ser- 
Table 4

Surveyed state programs that report collecting data on genetic counseling

\begin{tabular}{lccc}
\hline $\begin{array}{l}\text { Newborn } \\
\text { screening } \\
\text { conditions }\end{array}$ & $\begin{array}{c}\text { No. of states } \\
\text { that collect data } \\
\text { on genetic } \\
\text { counseling }\end{array}$ & $\begin{array}{c}\text { Percent of } \\
\text { total surveyed } \\
N=35\end{array}$ & $\begin{array}{c}\text { Percent of } \\
\text { U.S. states and } \\
\text { territories } \\
N=54\end{array}$ \\
\hline $\begin{array}{l}\text { Metabolic disorders } \\
\begin{array}{l}\text { Sickle cell disease } \\
\text { and other } \\
\text { hemoglobinopathies }\end{array}\end{array}$ & $8^{a}$ & $23 \%$ & $15 \%$ \\
$\begin{array}{l}\text { Endocrine disorders } \\
\text { Cystic fibrosis }\end{array}$ & 4 & $12 \%$ & $7 \%$ \\
\hline
\end{tabular}

${ }^{a}$ Eight states in total collected data on metabolic disease with a subset of these collecting data on other conditions.

${ }^{b}$ Of these eight states, three required cystic fibrosis screening at the time of this survey.

vices." 16 Although the guidelines acknowledged NBS as a highly successful, population-oriented service for secondary prevention, there was no reference to the relationship between provision of NBS and clinical genetic services. The guidelines listed a number of "essential linkages which should occur at every state level for the purposes of monitoring occurrence of specific genetic diseases, outcomes in infants/children with those diseases, and assessment of services utilization and efficiency of service delivery." Cited as essential were the routine linkage of NBS records with birth certificates, linkage between statewide clinical genetic services database and birth/fetal death certificates, and referral from clinical genetic services to early intervention services for infants and children aged less than 3 years. However, there was no reference to the linkage between NBS follow-up and clinical genetic services.

Multiple federally supported initiatives have been implemented to integrate genetics into public health. For example, HRSA/MCHB has funded a number of states and provided technical assistance for developing and implementing state genetic plans and supported the integration of NBS programs and their information systems with other related child health programs and information systems. ${ }^{17}$ The HRSA/MCHBfunded NNSGRC developed guidance for state and territorial programs on integrating genetic services into public health. Participation by internal stakeholders, including those within NBS, was noted to be essential to the development of a plan to achieve integration of genetics within existing programs. ${ }^{18} \mathrm{~A}$ national survey of state health departments (2001) found that public health genetics is well established in the area of maternal and child health and NBS. ${ }^{19}$

Recently, the Clinical and Laboratory Standards Institute Newborn Screening Follow-up Approved Guideline (2006) designated genetic counseling as a function of STFU. The guideline states that "All follow-up communications about an individual newborn should be documented in the newborn screening follow-up program's record, according to applicable rules and regulations. The record should be kept current and at a minimum, contain the following: diagnosed cases, referral information (e.g., subspecialty providers, support services, ge- netic counseling), enrollment in early intervention, and LTFU activities. For LTFU of affected individuals, programs should collect data regarding use of appropriate follow-up services. These data should be collected in collaboration with primary care and subspecialty providers, other medical and support service providers, and/or parents/affected individuals." ${ }^{5}$ It is encouraging that there is recognition of the need to document genetic counseling as part of NBS follow-up. Having such explicit guidelines for states may assist them in gaining resources to track information to monitor that newborns receive requisite genetic services. States with contractual arrangements with subspecialty providers are in a particularly favorable position to request detailed information on genetic services that subspecialists provide to newborns referred from the NBS program. We found that although few states reported that their NBS data systems link to the clinical subspecialties, there was acknowledgment from many of the respondents that such linkages would be useful in their communications and follow-up activities. Privacy legislation in specific states might impact the ability to create linkages and share information.

Recently, legislation was introduced in Congress to amend the Public Health Service Act to improve NBS activities. Section 2 of Senate Bill 3743 "Screening for Health of Infants and Newborns Act" states that "appropriate newborn screening evaluations should be conducted for all newborns to allow appropriate referrals and provisions for early medical intervention and newborn screening data collection should be standardized, and conditions detected by newborn screening should be tracked and monitored." 20 The bill authorizes funding for the development of recommended guidelines for NBS and data collection and guidelines for monitoring, evaluation, and surveillance of NBS. Thus, it is possible that federal funds will become available to help ensure that infants and their families with genetic disorders identified through NBS receive the full range of services, including clinical genetic services.

This study has several potential sources of error. First, the study represents self-reported data obtained from state public health staff members working in the areas of NBS and genetics. The majority of the survey respondents were cooperative and generous with their time and information. However, this study is limited by the fact that self-reported data are subject to bias. This assertion is supported by observations during the validation process, when two of the states altered their initial responses to collecting data on genetic counseling, for example, from "No, data system is in process," to "Yes, for some cases through the follow-up nurse." Survey respondents also had varying interpretations of the same questions, yielding responses that had nuances that complicated interpretation of results. For example, responses to the question on whether patient-level data on genetic counseling were collected had qualifying statements, for example, "Yes, but not routinely collected" and "Yes, but not on families who choose to be followed out of state."

A second source of potential error was staff turnover at the state programs during the course of the study. During the survey process, four state genetics coordinators, one state NBS 
Table 5

National Newborn Screening and Genetics Resource Center guidance to states for tracking clinical genetic services for newborns

1. Was the diagnosis identified by newborn screening confirmed by a subspecialty provider?
$\square$ Yes
№
Unknown

2. Was a genetic counseling referral made?
$\square$ Yes
$\square$ No
Subspecialty provider is a clinical geneticist and provided counseling
U Unknown

3. Did genetic counseling take place?
$\square$ Yes
$\square$ No
U Unknown

4. If yes, was the provider:
$\square$ MD Geneticist
व PhD Geneticist
BC/BE Genetic Counselor
MD Subspecialist, specify:
$\square$ Primary care provider
$\square$ Nurse
Other, specify:

5. Were the following subjects covered in genetic counseling:
Genetic basis of the disorder
$\checkmark$ Prenatal treatment (if appropriate)
- Risk estimation for future pregnancies
- Carrier testing
$\checkmark$ Impact on other family members
$\checkmark$ Prenatal diagnosis (if appropriate)

6. Was a letter/literature on genetic issues provided to the parents or other primary care givers?
$\square$ Yes
No
口 Unknown

7. Was a follow-up appointment to genetics clinic provided to the child and parents or other primary care givers?
$\square$ Yes
№
U Unknown

8. Was a report sent to:
$\square$ Medical home
Subspecialty provider
Newborn Screening Follow-up Program
प Unknown

9. If genetic services were provided, how were they financed:
$\checkmark$ Private insurance
Medicaid
Self-pay
Public Health Department
$\square$ Title $V$ funds

\section{$\square$ Newborn screening fees}
u Unknown

10. Were genetic tests provided?
$\square$ Yes
Please specify:
- DNA analysis
$\checkmark$ Other, specify:
$\square$ No
口 Unknown 
follow-up coordinator, and one dual role coordinator left their respective programs. This affected data collection insofar as it required additional contacts with staff to provide background on the survey and recollect results for three states during the process of validation. Two of the other states had responded jointly, and in the third, the departure of the state genetics coordinator was anticipated, so there was continuity in understanding about the survey.

Finally, it is possible that some of the states that screened out of the survey initially may actually be states that, although they do not collect data within their program, could access it through their subspecialist providers with whom they may have contractual agreements.

During the course of interview and validation processes, five states requested guidance in incorporating questions on their NBS referral forms that would help them track provision of clinical genetic services. In response, the NNSGRC has drafted a list of questions that programs can incorporate to track provision of these services (Table 5). This expression of interest, coupled with the fact that there are at least eight states that document genetic counseling, is a hopeful sign given the emphasis on STFU.

Until state NBS programs routinely collect data on provision of clinical genetic services for newborns, the question as to whether newborns and their families identified with conditions through NBS receive adequate genetic services cannot be answered objectively and certainly not for all conditions screened.

There are numerous elements favorable to states systematically tracking clinical genetic services for newborns identified through their NBS programs. Recent national guidelines address the need to include monitoring of genetic counseling in NBS follow-up. ${ }^{5}$ The Association of Maternal and Child Health Programs report on NBS LTFU (December 2006) states that "activities occurring after newborn screening and diagnosis which limit the health consequences of confirmed disorders are essential and a public health responsibility." ${ }^{21}$ There is awareness among many of the survey respondents about the importance of linkages with subspecialty providers and an expressed interest among some states for guidance on specific data points to collect. The communications processes that state programs use now to obtain reports from subspecialty providers could be augmented with questions about clinical genetic services, particularly among states with contractual arrangements with providers. The need for long-term monitoring and evaluation of NBS has been expressed repeatedly at recent national meetings, including those of the federal Advisory Committee on Heritable Disorders and Genetic Diseases in Newborns and Children. Federal legislation has been proposed to fund standardized NBS data collection that could feasibly address the need for the linkage between NBS and clinical genetic services.

With the recent expansions in number of conditions for which states screen, NBS programs and service providers are experiencing increased workload demands that could impact the momentum among states to ensure that newborns and their families receive the genetic services they need. It is hoped that these other favorable elements, including national legislation with appropriations, will create the environment for states to strive toward assuring newborns identified through NBS, and their families, receive the clinical genetic services they need. By working with states that have expressed an interest and ability in knowing whether newborns receive genetic services, appropriately secured data collection processes can be enhanced to begin to answer the question prospectively. The results of future patient-level data collection efforts can be shared with other states and federal entities to impact policy for the benefit of newborns and their families and maintain a highquality and successful NBS system.

\section{ACKNOWLEDGMENTS}

This project was supported through a cooperative agreement among the MCHB, Genetic Services Branch, and the University of Texas Health Science Center at San Antonio, Department of Pediatrics, HRSA Grant No. 6-U32-06-001/ MC00148. Opinions stated herein are those of the authors and not necessarily of the HRSA or Department of Health and Human Services. The authors express appreciation to the members of the Ad Hoc Expert Committee on the Definition of Genetic Services, David Flannery, MD, and Robert Saul, MD, representing American Academy of Pediatrics Section on Genetics and Birth Defects; Nancy Mendelsohn, MD, and Brad Schaefer, MD, representing the American Academy of Pediatrics Committee on Genetics, for their efforts on behalf of the NNSGRC. The authors also express appreciation to the following state NBS follow-up coordinators, state genetics coordinators, RCPIs, and others associated with the project for their gracious assistance: Carolyn Anderson, Janice Bach, Jennifer Brown, Bob Bowman, Thomas Brewster, MD, Margaret Bruch, Jannine Cody, PhD, Kathy Cummons, Gloria Deyhle, Roger Eaton, Sandy Fawbush, Suzanne Ficara, Lucy Fossen, Diane Frazier, MD, Mike Glass, Kelly Holland, Joyce Hooker, Mary Beth Hummel, MD, Cynthia Ingham, Melody Johnson, Fay Keune, Pam King, Mitzi Lamberth, Karen Lempke, David Martinez, Christine Matsumoto, Mary Carroll McCaffery, Mittie Moffet, Tara Morris, Ellie Mulcahy, John Mulvihill, MD, Kimberly Noble Piper, Claudia Nash, Sheila Neier, Shelley Nottingham, Carla Ortiz, Susan Panny, MD, Lara Percenti, Beryl Polk, Arlena Pugliese, Julie Raburn-Miller, Joyce Robl, Sharmini Rogers, MD, Brenda Romero, Barbara Schweitzer, Kirstin Schwandt, Kerry Silvey, Rani Singh, MD, Ann Spencer, Quinn Stein, Lois Taylor, Sharon Tiner, Kathy Tomashitis, Kathleen Velasquez, Betsy Voss, Jackie Whitfield, Thalia Wood, Bill Young, and Kristi Zonno.

\section{References}

1. Pass KA, Lane PA, Fernhoff PM, Hinton CF, et al. US Newborn Screening System Guidelines II: follow-up of children, diagnosis, management, and evaluation. Statement of the Council of Regional Networks for Genetic Services. J Pediatr 2000;137 (suppl):S1-S46.

2. Therrell BL, Panny SR, Davidson A, Eckman J, et al. US newborn screening system guidelines: statement of the Council of Regional Networks for Genetic Services. Screening 1992;1:135-147. 
3. American Academy of Pediatrics, Newborn Screening Task Force. Serving the family from birth to medical home. Newborn screening: a blueprint for the future. Pediatrics 2000;106 (suppl):383-427.

4. American College of Medical Genetics' Expert Group. Newborn screening: toward a uniform screening panel and system-executive summary. Genet Med 2006;8 (suppl):1S-11S.

5. Clinical Laboratory Standards Institute. Newborn screening follow-up: approved guideline. Wayne, PA: Volume 26, No. 18, May 2006.

6. Ciske DJ, Haavisto A, Laxova A. Genetic counseling and neonatal screening for cystic fibrosis: an assessment of the communication process. Pediatrics 2001;107:699-705.

7. American Academy of Pediatrics, Section on Hematology/Oncology, Committee on Genetics. Health supervision for children with sickle cell disease. Pediatrics 2002; 109:526-535.

8. American College of Medical Genetics' Expert Group. Newborn screening: toward a uniform screening panel and system—-main report. Genet Med 2006;8 (suppl):12S-53S.

9. National Newborn Screening and Genetics Resource Center. Available at: http:// genes-r-us.uthscsa.edu. Accessed August 1, 2006.

10. Therrell BL. US newborn screening policy dilemmas for the twenty-first century. Mol Genet Metab 2001;74:64-74

11. Centers for Disease Control and Prevention. Update: newborn screening for sickle cell disease-California, Illinois, and New York, 1998. MMWR Morb Mortal Wkly Rep 2000;49:729-731.

12. Hoff T, Hoyt A. Practices and perceptions of long-term follow-up among state newborn screening programs. Pediatrics 2006;117:1922-1929.
13. McDowell I, Newell C. Measuring health: a guide to rating scales and questionnaires, 2nd ed. New York: Oxford University Press, 1996.

14. Farrell MH, Certain LK, Farrell PM. Genetic counseling and risk communication services of newborn screening programs. Arch Pediatr Adolesc Med 2001:120-126.

15. Council of Regional Networks for Genetic Services (CORN). Guidelines for the clinical genetic services for the public's health. 1st edition. Atlanta, GA: CORN, 1997.

16. Kirby R. Analytical resources for assessment of clinical genetic services in public health: current status and future prospects. Teratology 2000;61:9-16.

17. Maternal and Child Health Bureau. Incorporating genetic medicine and technology into practice and service, 1999. Available at: http://mchneighborhood.ichp.edu/ GeneticsMeeting 1999/meeting2agenda.htm. Accessed August 1, 2006.

18. Kaye CI, Laxova R, Livingston JE, Lloyd-Puryear MA, et al. Integrating genetic services into public health- guidance for state and territorial programs from the National Newborn Screening and Genetics Resource Center (NNSGRC). Community Genet 2001;4:175-196.

19. Piper MA, Bryan JL, Lindenmayer JM, Lengerich EJ, et al. The role of state public health agencies in genetics and disease prevention: results of a national survey. Public Health Rep 2001;116:22-31.

20. 109th Congress, 2D Session. S. 3743. A bill to amend the Public Health Service Act to improve newborn screening activities, and for other purposes. Available at: http:// www.congress.org/. Accessed September 8, 2006.

21. Association of Maternal and Child Health Programs. Newborn screening long-term follow-up assessment. January 2007. Available at: http://www.amchp.org/aboutamchp/ publications/NBS-LTFU\%20Assessment.pdf. Accessed July 11, 2007. 